\title{
Social Desirability in Virtual Communities
}

\author{
Francesco Massara \\ Assistant Professor of Marketing, Department of Economics and Marketing, IULM University \\ Via Carlo Bò 1, 20143 Milano, Italy \\ Tel: 39-2-891-412-746 E-mail: francesco.massara@iulm.it
}

Fabio Ancarani

Professor of Marketing, Alma Mater Studiorum University of Bologna

Piazza della Vittoria 15, 47100 Forlì, Italy

Michele Costabile

Professor of Marketing, LUISS Guido Carli University

Viale Pola 12, 00198 Rome, Italy

Francesco Ricotta

Associate Professor of Marketing, Sapienza University of Rome

Via del Castro Laurenziano 9, 00161 Roma, Italy

Received: September 24, 2012

Accepted: November 3, $2012 \quad$ Online Published: November 9, 2012

doi:10.5430/ijba.v3n6p93

URL: http://dx.doi.org/10.5430/ijba.v3n6p93

\begin{abstract}
As virtual worlds and social media in general become important settings for marketing actions, we need to know what is the weight of social norms within such contexts. To what degree can a researcher expect that the answers obtained within a virtual world - ultimately a social network - reflect real opinions and are not inflated by social desirability? Does the social context of an online community induce higher social desirability? This paper investigates whether social desirability is stronger within virtual world online communities than in the real world, observing same structural relationship among measured constructs but higher social desirability tendency in the virtual world compared to the real life. Since social networks and online communities will be more often used as research and communication platforms, increased attention needs to be paid to the social desirability tendency of the community members.
\end{abstract}

Keywords: Social desirability, Social networks, Online communities, Virtual worlds

\section{Introduction}

Recently virtual worlds have become popular, engaging millions of participants around the world. This rapid growth has attracted the attention of researchers (Novak 2010), companies (Business Week 2006), and governments (The Guardian 2007) in search of new opportunities for education, research, and business. Given the striking similarities between behaviors in virtual worlds and in the offline world, the opportunity to use virtual worlds as subject pools for research is considered very promising by many social scientists (Bailenson 2007). This paper considers this possibility worthy of investigation and assesses the social desirability in online communities, an issue which, surprisingly, has not been addressed before.

When studies first reported that social, psycho-physical, and economic behaviors enacted in virtual worlds are consistent with those in real life (Gorini, Gaggioli and Riva 2007; Miller 2006), researchers became interested in how to leverage this fact to better understand social and marketing phenomena (Hemp 2006; Bainbridge 2007).

A striking resemblance between real- and virtual-world behaviors has been recorded by Yee and others (2007), who found that in virtual worlds people maintain a certain distance when talking to each other, and that female-female pairs 
make more eye contact and stand closer together as they interact, just as in the real world. Thus, a perception of spatial distance and, more importantly, the rules of proxemics are imported from real- to virtual-world interactions. In another study, Yee and Bailenson (2007) noted a resemblance in behaviors concerning touch. People applied a softer touch (measured using a sensitive joystick) when asked to touch a body than when asked to touch an inanimate object. Differences were also noted for different parts of the body (softer touch for face compared to torso) and gender (softer when touching females instead of males). Chesney Chuah and Hoffmann (2009) reported that economic behavior tested via a series of experiments (games) in Second Life resembles the results of other lab and field experiments of the same type, as reported in the literature of economic behavior.

Beyond the consistency of one-to-one social interactions and psychophysical and economic behaviors, a relevant issue for social science researchers is to establish to what extent answers given within virtual worlds can be affected by social norms. In other words, to what degree can one expect that the answers given within a virtual world - ultimately a social network - reflect real opinions and are not inflated by social desirability. Two intertwining factors alert on the fact that social networks can be affected by higher social desirability tendency than the real norm. The first factor is inherent to the social response theory (Reeves and Nass 1996), which contends that, in a computer-mediated context, the use of social cues (i.e., language, human voice, interactivity, social roles, etc.) elicits socially desirable responses (e.g., taking responsibility for negative outcomes) (Moon 2000; Moon 2003) and promotes behaviors that regularly occur in person-to-person interactions (Wang et al. 2007). The effect of social responses in human-computer interactions has been largely supported in the context of commercial websites, where the presence of a suitable avatar during the interaction enhances the perception of reciprocity and friendliness (Holzwarth, Janiszewsky, and Neumann 2006). Together, these studies support the idea that ordinary social behavior applies to avatar-mediated interaction and, therefore, to interactions in the context of virtual worlds as well.

There is additional evidence from the social interaction literature which tends to reinforce the reasoning that virtual worlds contexts emphasize social desirability. First, the interactions going on in virtual worlds, as in many virtual communities, are publicly shared, creating a sense of community through a commitment to shared values and norms which is stronger than real life, where the interactions are prevalently of the type one-to-one (Etzioni and Etzioni 1999). The ease of both one-to-one and one-to-many interaction that makes virtual communities so unique boosts the density and connectivity of the virtual social network. Both density and connectivity are, in the social capital literature, characteristics associated with ease of knowledge exchange and accessibility of the other members of the network (Chua 2002), thus virtual worlds should have structurally stronger networks than real life. Not only the structural dimension of the network is important, but the online social networks are also places where relations and norms of cooperation develop among group members, therefore the relational dimension comes into play (Coleman 1990; Putnam 1993). Finally, it is also noticeable that groups are very likely to be formed because of shared interests, and commonly shared language, which makes the members within each group more similar in terms of categorizations and shared systems of meaning (Nahapiet and Ghoshal 1998). Further than the major dimensions of the social interaction, there are other reasons which are more specific of the peculiar way of interacting within virtual worlds or online communities that supports such an interpretation. One of these is that although virtual worlds enhance human-computer interaction with the use of a visual technology, most social exchanges happen through textually transmitted information, which are more subject to control than other type of communication (Burnett and Bonnici 2003). Such tendency to pay more attention to what is communicated extends to attitudinal conformity (Merton 1959) and constitutes an additional factor which would lead to increased attention to conform to generally acknowledged social norms than it would happen in the real world.

For the reasons just pointed out social ties within virtual worlds are stronger than in real life, and this may lead to a stronger social desirability bias. The paper provides support for such a statement.

\section{Materials and Method}

\subsection{Research Design}

A survey on a bipartisan socially relevant issue (i.e., the adoption of an environmentally friendly electric car) was conducted in two different contexts: in the virtual world Second Life and offline in a classroom. Online participants were recruited through announcements both within the virtual world and on websites dedicated to the virtual world. Avatars were offered compensation for their participation in Linden Dollars (the internal currency of the virtual world). Participants visited a virtual consumer lab located in Second Life, which was given the fantasy name Cubesurveys (see Figure 1).

$<$ Insert Figure 1 Here $>$ 
When participants approached the consumer lab, they were directed to one of the cubicles where the survey apparatus was set up. Upon arrival, avatars were invited to participate in the survey (see Figure 2). After participants selected either Italian or English as their preferred language from a pop-up window, the survey opened in a web-browser window. After completion of the survey, each avatar was able to redeem their reward.

After three months, a total of 2,785 participants from all over the world had taken part in the survey. The majority of participants $(56 \%)$ were Italian, probably because Italian forums were primarily used to advertise the research. To control for opportunistic behavior of participants who might, for example, answer inaccurately just to cash in on the promised reward, the time taken to provide answers was covertly traced for each page of the questionnaire. Pre-test data suggested that at least 2 minutes were required to swiftly read and respond to the overall questionnaire. Ultimately all of the questionnaires that had been completed in less than 2 minutes were eliminated. The average time taken for the Italian online sample was $3 \mathrm{~min} 45 \mathrm{sec}$, and the average time for the international sample was $4 \mathrm{~min} 04 \mathrm{sec}$. A total of 575 questionnaires were eliminated, almost $21 \%$ of the sample. The final data set was thus composed of 2,200 valid questionnaires, with the proportion of the Italian subsample rising to $67 \%$, or 1,480 questionnaires. The remaining 720 international participants were mostly Europeans (50\%), North Americans (28\%), and South Americans (10\%).

The offline sample was composed of 186 questionnaires, which were collected in classrooms at four Italian universities during the same time period as the online study. Offline participants were students, all in the age range 20-29 and mostly female (69\%). Because age significantly differentiated the answers in the Italian online subsample, but not in the international online subsample, the analysis was restricted to the 20-29 age class for both of the online subsamples. In the Italian and international online subsamples, females were outnumbered by males $(41 \%$ female and $46 \%$ female, respectively). The time required for completion was calculated by asking offline participants to indicate the time at the beginning and at the end of the questionnaire. The average time required for completion was slightly higher for offline participants at $5 \mathrm{~min} 20 \sec (F(2,1080)=30.45 ; \mathrm{p}<0.1)$. Gender did not lead to significant differences across the three subsamples for none of the metrics. The final sample was composed of 1,082 valid questionnaires: 186 of these were offline Italian participants (Sample 1), 560 were online Italian participants (Sample 2), and the remaining 336 were international online participants (Sample 3).

\subsection{Metrics}

A questionnaire on environmental protection, a socially relevant issue that is widely known was developed. The introduction to the questionnaire stated that the intent of the study was to measure environmentally friendly behavioral intentions (i.e., switching to an electric car). Existent measures of environmental consciousness developed by Kaiser, Wolfing, and Fuhrer (1999) were used (see Appendix A). General knowledge of environmental issues was measured with two dichotomous items. Attitude toward environmental safety was measured with five items on a 9-point Likert scale. The metric concerning beliefs about the importance of environmental issues were measured with four dichotomous items. Behavioral intentions were measured with a single question using a 9-point Likert scale. The measures of knowledge and values were calculated by summing item ratings. Exploratory and confirmatory factor analysis as well as reliability analysis of the environmental attitude scale conducted on the overall sample and on the three subsamples separately suggested to that only two of the initial five items should be kept (Alpha $=0.62$; Extracted Variance $=72.6 \%$ ).

For the Italian questionnaire, the scales were translated using procedures previously applied in marketing research studies (Griffin, Babin, and Modianos 2000). The items were translated into Italian by a native speaker. A native English speaker back-translated the text into English, which was then compared with the original and exhibited no relevant differences. This procedure guaranteed translational equivalence for the scale items.

\section{Results}

Construct means, standard deviations, and correlation coefficients for the three samples are listed in Table 1. A comparison of descriptive statistics revealed different levels across the three samples; however, the structure of the causal relationships among the constructs was fairly consistent.

$<$ Insert Table 1 Here>

Consistent with the proposed hypothesis, between the two Italian samples there was a significant difference in the stated behavioral intentions, with the Italian sample online showing higher propensity towards a socially desirable answer than that offline $\left(\mathrm{F}_{\text {bintentions }}(1,743)=10.03 ; \mathrm{p}<0.01\right)$. The measures of knowledge and value differed significantly between the two samples $\left(\mathrm{F}_{\text {knowledge }}(1,743)=8.94 ; \mathrm{p}<0.01 ; \mathrm{F}_{\text {value }}(1,743)=5.99 ; \mathrm{p}<0.05\right)$, but attitude, which is more exposed social influence (Merton 1959), was consistent across the samples ( $\mathrm{F}_{\text {knowledge }}(1,743)=1.29$; NS). The overall direct effect of context (online-offline) on social desirability was significant, but this time attitude 
$\left(\mathrm{F}_{\text {attitude }}(1,1080)=3.64\right.$.; $\left.\mathrm{p}<0.10\right)$, further than behavioral intentions $\left(\mathrm{F}_{\text {bintentions }}(1,1080)=4.23 ; \mathrm{p}<0.05\right)$ was very close to significance and in the predicted direction.

Additional analyses were run to ensure that the bias that was found affecting only the strength of the valence attributed to behavioral intentions, but not the overall causal inference. A biased answer in fact, results in a "face response", but the reasoning behind the answer should be the same. In other words, the form should change but the substance should remain intact. The correlations between the variables exhibited consistency across the three samples, the only differences being: 1) the non-significance of the relationship between attitude and values for Sample 1, and 2) the significant correlation between environmental attitude and behavioral intentions for the international sample.

To further test whether there was consistency in the causal structure among the constructs between the different contexts, a regression model was run with behavioral intentions as a dependent variable and knowledge, environmental attitude, and values as explanatory variables.

Table 2 summarizes the results of linear regressions. Despite the weakness of the relationship between dependent and independent variables, there was a perfect correspondence in the results of the regression analysis between Sample 1 and Sample 2.

$<$ Insert Table 2 Here $>$

The sign of the parameter estimates and their significance matches exactly. Additionally, the independent variables exert the same level of influence on the dependent variable; that is, the marginal effects of the independent variables on the dependent variable are equal. Sample 3 differs in that attitude is a significant predictor of behavior, but the same perfect correspondence between sign of the parameters, significance levels, and marginal effects of the independent variables on the dependent variable. Because Sample 3 is an international sample, some differences from the Italian samples would be somewhat expected, although it is beyond the scope of this paper to theoretically justify these results. Chow tests comparing the three samples confirmed that the coefficients did not differ between Sample 1 and Sample 2 $(\mathrm{F}(3,738)=0.53$; NS $)$, but that they did differ between Samples 1 and $3(\mathrm{~F}(3,980)=11.61 ; \mathrm{p}<0.01)$, as well as between Samples 2 and $3(\mathrm{~F}(3,514)=4.54 ; \mathrm{p}<0.05)$.

In conclusion, the hypothesis that virtual worlds are affected by higher social desirability found support, and the causal inference investigated (i.e., explanation of behavioral intentions concerning environmental issues), was not affected at all. This shows that inferences about cause-effect relationships from research in virtual worlds can be generalized to other settings, but it also supports the existence of a social desirability bias in virtual worlds.

\section{Conclusion}

This paper compared answers provided in a virtual world context with answers provided in a offline context on the general bipartisan issue of environmentally-friendly automobiles finding that virtual worlds are affected by social desirability more than the real world. A biased response (higher behavioral intentions and attitudes) was expressed from the sample of participants in the virtual world, and overall the causal relationships among the constructs investigated were identical between two of the three samples, and fairly stable across all three samples.

A limitation of the study is that the evidence relates to situations where the answer: 1) does not have any direct personal implications and 2) carries a low level of risk. Since avatar appearance has been found to increase likeability and self-confidence, which affects behavior in certain situations (Holzwarth, Janiszewsky, and Neumann 2006; Yee and Bailenson 2007), then one would expect that avatar-mediated interaction and avatars' role playing can at times change the response to be more or less socially desirable, especially when the response would have some implications for the avatar. Nevertheless a social desirability bias was found to exists in the situation investigated.

Another consideration directly connected to virtual worlds research is that self-judgments (e.g., self-attributions of responsibility), either indirect or direct, were not taken into account. Bessière, Seay, and Kiesler (2007) concluded that multiplayer online game participants expressed more favorable evaluations of their avatars than they did of themselves. More precisely, these players revealed that their avatars were more similar to their ideal self than they themselves were. Thus, answers obtained from an avatar in a virtual world may be responses from an idealized character, reflecting cognitions of an "upgraded personality" that would not necessarily match that of the person sitting behind the computer screen in the real world. If the same kind of bias is reflected from the individual to the context, this would add some theoretical support to the hypothesis of higher social desirability. If the virtual world is the world of an "ideal self", the consequence being that the virtual world is generally better than the real, then such betterness should be reflected in the social interactions with the result that more friendly and socially prone behavior should be noticed within the boundaries of the virtual world. 
In this respect, it would be useful to repeat the study in non-avatared virtual communities such as in social networks. Recent studies support that communities and social networks in particular thrive and grow if conformism and reciprocity is fostered among the community members (Facchetti, Iacono and Altafini 2011). A straightforward support for such a view comes from the most popular social network Facebook, where the members are encouraged to like but not to dislike what other members do. To the extent that in social network participants reveal their true identities, the existence of rules of conduct or restrictions that minimize hostile relationships within the network may exacerbate the need for conformity leading to an even stronger social desirability bias. Since social networks are much larger research pools than virtual worlds, it would be very useful to know the dimension of the bias, as well as, and more importantly, the difference between socially manifest intentions and real behavior.

\section{References}

Bainbridge, W.S. (2007). The Scientific Research Potential of Virtual Worlds. Science, 317(5837), 472-476. http://dx.doi.org/10.1126/science.1146930

Bessière, K.M.A., Seay, A.F., \& Kiesler, S. (2007). The Ideal Elf: Identity Exploration in World of Warcraft. Cyberpsychology and Behavior, 10(4), 530-535. http://dx.doi.org/10.1089/cpb.2007.9994

Burnett, G., \& Bonnici L. (2003). Beyond the FAQ: Explicit and Implicit Norms in Usenet Groups. Library \& Information Science Research, 25(3), 333-351.

Business Week. (2006). IBM to Open Islands in Virtual World. December 12.

Chesney, T., Chuah, S., \& Hoffmann, R. (2009). Virtual World Experimentation: An Exploratory Study. Journal of Economic Behavior and Organization, 72, 618-635.

Chua, A. (2002). The Influence of Social Interaction on Knowledge Creation. Journal of Intellectual Capital, 3(4), 375-392. http://dx.doi.org/10.1108/14691930210448297

Coleman, J.S. (1990). Foundations of Social Theory. Cambridge, MA: Belknap Press of Harvard University Press.

Etzioni, A., \& Etzioni, O. (1999). Face-to-Face and Computer-Mediated Communities: A Comparative Analysis. The Information Society, 15, 241-248. http://dx.doi.org/10.1080/019722499128402

Facchetti, G., Iacono, G., \& Altafini, C. (2011). Computing Global Structural Balance in Large-scale Signed Social Networks. PNAS, 108(52), 20953-8. http://dx.doi.org/10.1073/pnas.1109521108

Gorini, A., Gaggioli, A., \& Riva, G. (2007). Virtual Worlds, Real Healing. Science, 318(5856), 1549. http://dx.doi.org/10.1126/science.318.5856.1549b

Griffin, M., Babin, B.J., \& Modianos, D. (2000). Shopping Values of Russian Consumers: The Impact of Habituation in a Developing Economy. Journal of Retailing, 76(1), 33-52. http://dx.doi.org/10.1016/S0022-4359(99)00025-1

Hemp, P. (2006, June). Avatar-Based Marketing. Harvard Business Review, 48-57.

Holzwarth, M., Janiszewski, C., \& Neumann, M.M. (2006, October). The Influence of Avatars on Online Consumer Shopping Behavior. Journal of Marketing, 70, 19-36. http://dx.doi.org/10.1509/jmkg.70.4.19

Kaiser, F., Wolfing, S., \& Fuhrer, U. (1999). Environmental Attitude and Ecological Behavior. Journal of Environmental Psychology, 19(1), 1-19. http://dx.doi.org/10.1006/jevp.1998.0107

Merton, R.K. (1959). Social Conformity, Deviation, and Opportunity-Structures: A Comment on the Contributions of Dubin and Cloward. American Sociological Review, 24(2), 177-189. http://dx.doi.org/10.2307/2089428

Miller, G. (2007). The Promise of Parallel Universes. Science, 317(5842), 1341-1343. http://dx.doi.org/10.1126/science.317.5843.1341

Moon, Y. (2000). Intimate Exchanges: Using Computers to Elicit Self-Disclosure from Consumers. Journal of Consumer Research, 36(March), 324-340. http://dx.doi.org/10.1086/209566

Moon, Y. (2003). Don't Blame the Computer: When Self-Disclosure Moderates the Self-Serving Bias. Journal of Consumer Psychology, 13(1\&2), 125-137. http://dx.doi.org/10.1207/S15327663JCP13-1\&2_11

Nahapiet, J., \& Ghoshal, S. (1998). Managing Knowledge in Global Service Firms: Centres of Excellence. Academy of Management Executive, 12(4), 81-92.

Novak, T.P. (2010). Elab City: A Platform for Academic Research on Virtual Worlds. Journal of Virtual Worlds Research, 3(1), 3-33.

Putnam, R.D. (1993). The Prosperous Community: Social Capital and Public Life. American Prospect, 13, 35-42. 
Reeves, B., \& Nass, C.I. (1996). The Media Equation. Stanford, CA: Cambridge University Press.

The Guardian. (2007, November). Virtual China Looks for Real Benefits, (1).

Wang, L.C., Baker, J., Wagner, J., \& Wakefield, K. (2007). Can a Retail Web Site Be Social? Journal of Marketing, 71(July), 143-157. http://dx.doi.org/10.1509/jmkg.71.3.143

Yee, N., \& Bailenson, J.N. (2007). The Proteus Effect: The Effect of Transformed Self-Representation on Behavior. Human Communication Research, 33, 271-290. http://dx.doi.org/10.1111/j.1468-2958.2007.00299.x

Yee, N., Bailenson, J.N., Urbanek, M., Chang, F., \& Merget, D. (2007). The Unbearable Likeness of Being Digital: The Persistence of Nonverbal Social Norms in Online Virtual Environments. Journal of CyberPsychology and Behavior, 10(1), 115-121. http://dx.doi.org/10.1089/cpb.2006.9984

Table 1. Descriptive statistics and pearson correlations

Sample 1 (offline Italian participants) - N = 186

\begin{tabular}{|r|c|c|c|c|c|c|}
\hline \multicolumn{1}{|c|}{ Construct } & Mean & SD & $(\mathrm{BI})$ & $(\mathrm{K})$ & $(\mathrm{A})$ & $(\mathrm{V})$ \\
\hline Behavioral Intentions (BI) & 6.83 & 2.48 & 1 & 0.07 & -0.1 & $0.22^{* *}$ \\
\hline Knowledge (K) & 1.82 & 0.40 & & 1 & 0.05 & $0.13^{*}$ \\
\hline Attitude (A) & -0.12 & 0.94 & & & 1 & 0.10 \\
\hline Values (V) & 3.10 & 0.82 & & & & 1 \\
\hline
\end{tabular}

Sample 2 (online Italian participants) $-\mathbf{N}=\mathbf{5 6 0}$

\begin{tabular}{|r|c|c|c|c|c|c|}
\hline \multicolumn{1}{|c|}{ Construct } & Mean & SD & $(\mathrm{BI})$ & $(\mathrm{K})$ & $(\mathrm{A})$ & $(\mathrm{V})$ \\
\hline Behavioral Intentions (BI) & 7.46 & 2.46 & 1 & $-0,01$ & 0.05 & $0.22^{* * *}$ \\
\hline Knowledge (K) & 1.70 & 0.53 & & 1 & -0.03 & $0.09^{*}$ \\
\hline Attitude (A) & -0.21 & 0.93 & & & 1 & $0.11^{* *}$ \\
\hline Values (V) & 2.92 & 0.92 & & & & 1 \\
\hline
\end{tabular}

Sample 3 (international online participants) - N = 336

\begin{tabular}{|r|c|c|c|c|c|c|}
\hline \multicolumn{1}{|c|}{ Construct } & Mean & SD & $(\mathrm{BI})$ & $(\mathrm{K})$ & $(\mathrm{A})$ & $(\mathrm{V})$ \\
\hline Behavioral Intentions (BI) & 6.85 & 2.49 & 1 & 0.08 & $0.31^{* * *}$ & $0.25^{* * *}$ \\
\hline Knowledge (K) & 1.59 & 0.59 & & 1 & -0.04 & $0.10^{*}$ \\
\hline Attitude (A) & 0.43 & 1.00 & & & 1 & $0.11^{*}$ \\
\hline Values (V) & 2.62 & 1.02 & & & & 1 \\
\hline
\end{tabular}

$* \mathrm{p}<0.05$

$* * \mathrm{p}<0.01$

$* * * \mathrm{p}<0.001$

Table 2. Results of regression analyses

Sample 1 (offline Italian participants) - N = 186

\begin{tabular}{|c|c|c|c|c|}
\hline & \multicolumn{4}{|c|}{ Independent Variable } \\
\hline Dependent Variable & $\begin{array}{c}\text { Knowledge } \\
(\mathrm{K})\end{array}$ & $\begin{array}{c}\text { Attitude } \\
(\mathrm{A})\end{array}$ & $\begin{array}{c}\text { Values } \\
(\mathrm{V})\end{array}$ & $\mathrm{R}^{2}$ \\
\hline $\begin{array}{c}\text { Behavioral } \\
\text { Intentions } \\
(\mathrm{BI})\end{array}$ & $0.05_{\mathrm{ns}}$ & $-0.04_{\mathrm{ns}}$ & $0.22^{* *}$ & 0.05 \\
\hline
\end{tabular}

Sample 2 (online Italian participants) $-\mathbf{N}=\mathbf{5 6 0}$

\begin{tabular}{|c|c|c|c|c|}
\hline & \multicolumn{3}{|c|}{ Independent Variables } \\
\hline Dependent Variable & $\begin{array}{c}\text { Knowledge } \\
(\mathrm{K})\end{array}$ & $\begin{array}{c}\text { Attitude } \\
(\mathrm{A})\end{array}$ & $\begin{array}{c}\text { Values } \\
(\mathrm{V})\end{array}$ & $\mathrm{R}^{2}$ \\
\hline $\begin{array}{c}\text { Behavioral } \\
\text { Intentions } \\
(\mathrm{BI})\end{array}$ & $-0.03_{\mathrm{ns}}$ & $0.02_{\mathrm{ns}}$ & $0.22^{* * *}$ & 0.05 \\
\hline
\end{tabular}


Sample 3 (international online participants) $-\mathbf{N}=\mathbf{3 3 6}$

\begin{tabular}{|c|c|c|c|c|}
\hline & \multicolumn{3}{|c|}{ Independent Variables } \\
\hline Dependent Variable & $\begin{array}{c}\text { Knowledge } \\
(\mathrm{K})\end{array}$ & $\begin{array}{c}\text { Attitude } \\
(\mathrm{A})\end{array}$ & $\begin{array}{c}\text { Values } \\
(\mathrm{V})\end{array}$ & $\mathrm{R}^{2}$ \\
\hline $\begin{array}{c}\text { Behavioral } \\
\text { Intentions } \\
(\mathrm{BI})\end{array}$ & $0.07_{\mathrm{ns}}$ & $0.28 * * *$ & $0.22 * * *$ & 0.14 \\
\hline
\end{tabular}

ns $=$ non-significant

$* \mathrm{p}<0.05$

$* * \mathrm{p}<0.01$

$* * * \mathrm{p}<0.001$

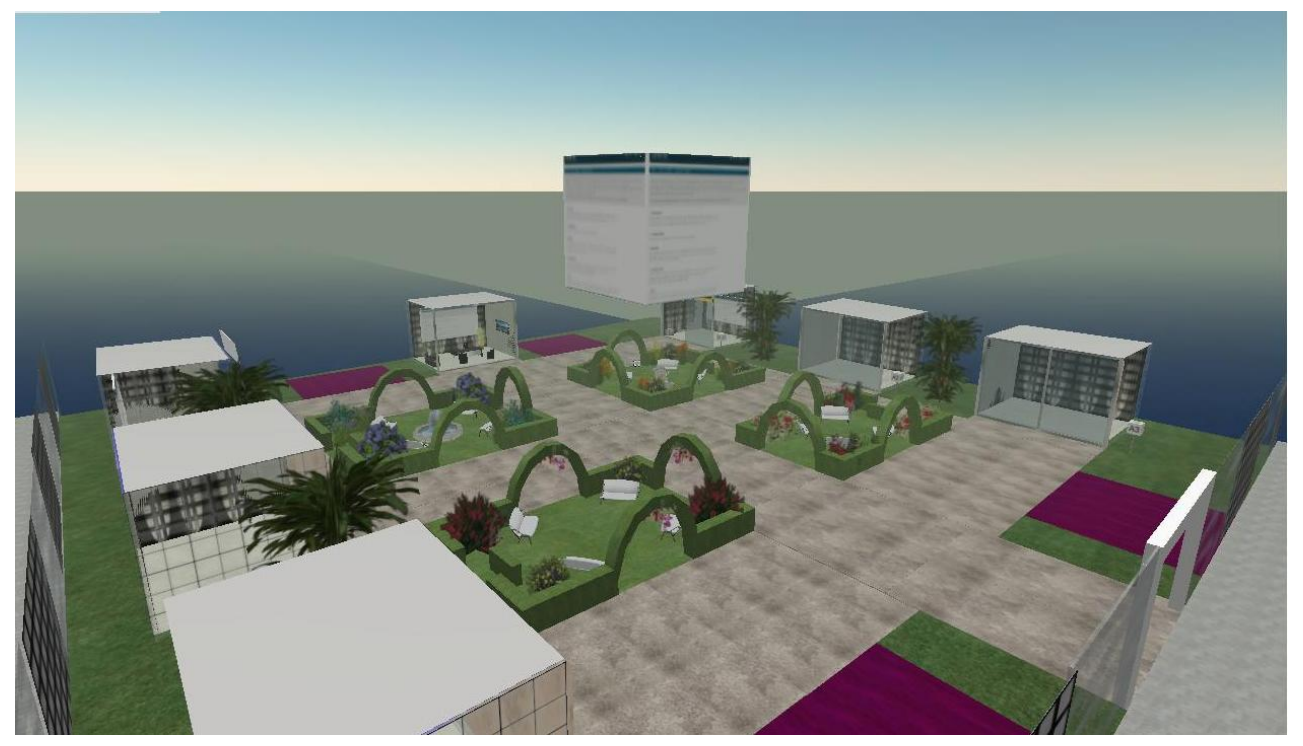

(a) view of the Cubesurveys consumer lab in Second Life

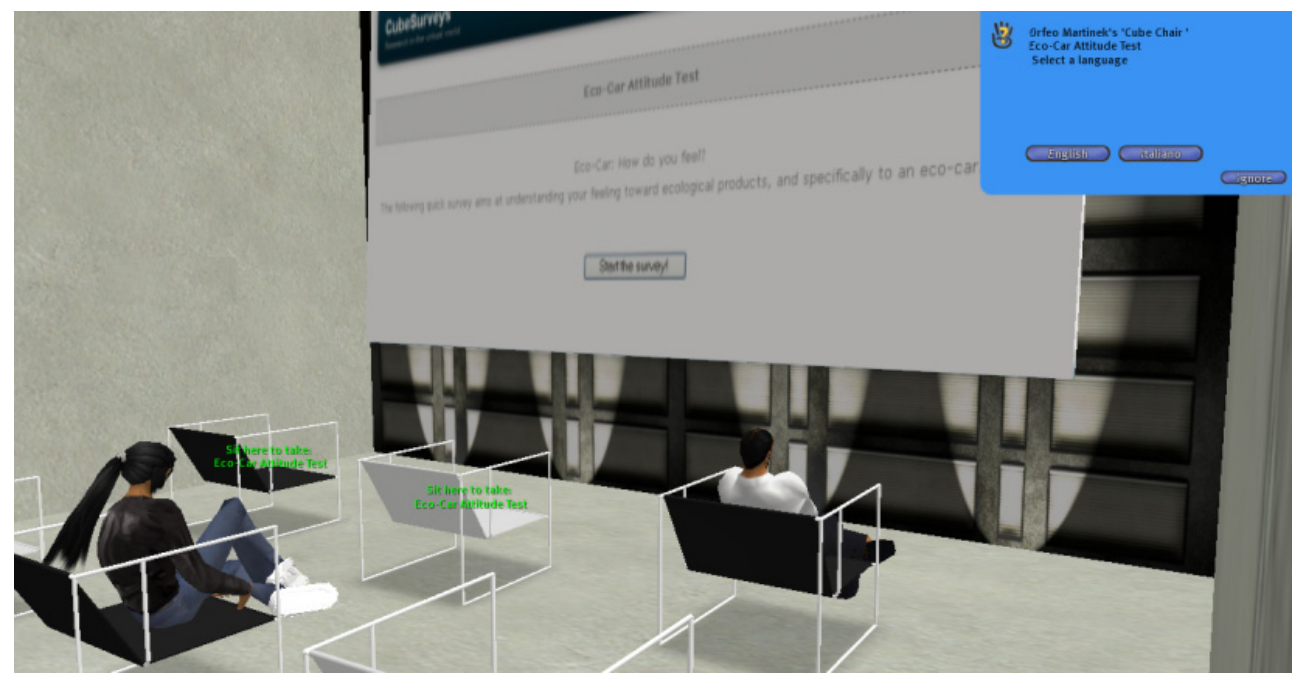

(b) two avatars completing the survey

Figure 1. The experimental setting in the virtutual world 


\section{Appendix A}

Online questionnaire (Note 1)

Eco-Car: How do you feel?

The following quick survey aims at understanding your feelings toward ecological products, and specifically towards an eco-car.

\section{Please answer the following question by clicking on YES or NO:}

1. Animals should have legal rights.

2. A change in climate caused by increased levels of $\mathrm{CO}_{2}$ in the atmosphere is called the greenhouse effect.

3. The greenhouse effect does not result in the melting of glaciers in central Europe.

4. Mass media shows environmental problems in a more pressing and serious way than in reality.

5. In the future, technological progress will bring solutions to ecological problems.

6. The quality of an environmentally friendly product is lower in comparison to its conventional alternative.

\section{Please answer the following statements by clicking on one of the stars, from the lowest (1) - meaning "probably no"} to the highest (9), meaning "probably yes," and 5 meaning "undecided":

7. For everything that I do including deeds affecting the environment, I am responsible to a supernatural force, for instance God.

8. I support raising parking fees in cities.

9. I am ready to pay environmental taxes (e.g., raising fuel or automobile taxes).

10. I will stop the engine at red lights in the future.

11. With their behavior, consumers can contribute most to the protection of the environment.

12. If you were given the chance to purchase a low-emission car, would you trade in your current vehicle?

Note

Note 1. Items 2 and 3 measure knowledge; items 1, 4, 5, and 6 measure values; items 7 through 11 measure attitudes; and item 12 measures behavioral intentions. Age, gender, and nationality were recorded on a separate page not reported here. 